Journal of Antimicrobial Chemotherapy (1986) 17, Suppl. C, 127-139

\title{
Clinical experience with Timentin in severe hospital infections
}

\author{
P. R. Meylan, ${ }^{a}$ T. Calandra, ${ }^{a}$ P. A. Casey ${ }^{b}$ and M. P. Glauser ${ }^{\circ}$ \\ 'Division of Infectious Diseases, Department of Internal Medicine, Centre Hospitalier \\ Universitaire Vaudois, Lausanne, Switzerland and Beecham AG, Bern, Switzerland
}

\begin{abstract}
Sixty-four severe infections in hospitalized patients were treated with intravenous Timentin. Most patients (mean age: 50.5 years, range $18-85$ ) had serious underlying conditions such as agranulocytosis, heart failure, cancer, diabetes mellitus, chronic alcoholism or other functional or anatomical abnormalities. Forty-three episodes were bacteriologically proved, and bacteraemia was diagnosed in 18 . The sites of infection were: lower respiratory tract (10), upper respiratory tract (10), soft tissues (9), urinary tract (7), bones (6), peritoneal cavity (3), meninges (1) and pelvis (1). In addition, 13 episodes of fever and four of septicaemia in patients with agranulocytosis were treated with Timentin plus amikacin. Overall, 59\% of the episodes were cured, $14 \%$ improved and $17 \%$ failed to respond. In $9 \%$ of cases the efficacy of the Timentin was unassessable mainly because of concurrent administration of other antimicrobials. Failure appeared to be more frequent in soft tissue and intra-abdominal infections, in patients infected with bacteria susceptible to Timentin but resistant to ticarcillin and in patients superinfected with Timentinresistant strains. Major side effects were haemorrhagic diathesis with platelet dysfunction (1), severe water sodium overload (1), and possibly pancreatitis (1). Other side effects were mild: catheter-related phlebitis, and abnormal but clinically insignificant laboratory test results. Timentin appears to be an effective and safe broad-spectrum combination which compares favourably with third-generation cephalosporins in the treatment of severe hospital infections. More experience is needed to decide whether the somewhat lower response rate in patients infected with ticarcillin-resistant strains is significant.
\end{abstract}

\section{Introduction}

Clavulanic acid, a potent inhibitor of bacterial $\beta$-lactamases, prevents destruction of penicillins by $\beta$-lactamase-producing organisms (Hunter et al., 1980; Neu \& Fu, 1978). The addition of clavulanic acid extends the spectrum of ticarcillin to include $\beta$ lactamase-producing strains of Staphylococcus aureus, Enterobacteriaceae, Gramnegative anaerobic rods, Haemophilus influenzae and some strains of Pseudomonas aeruginosa (Casey \& Glauser, 1983; Lamothe, Auger \& Lacroix, 1984; Fuchs et al., 1984; Barry et al., 1984; Clarke \& Zemcov, 1984; Hunter et al., 1980). The availability of an intravenous formulation of ticarcillin plus clavulanic acid (Timentin) prompted its clinical trial in the treatment of severe hospital infections.

\section{Materials and methods}

In-patients at the Centre Hospitalier Universitaire Vaudois, Lausanne, who required broad-spectrum antibiotic therapy for severe infections were eligible for inclusion in the 127

$0305-7453 / 86 / 17 \mathrm{C} 127+13 \$ 02.00 / 0$

(C) 1986 The British Society for Antimicrobial Chemotherapy 
study. Patients excluded were those with penicillin hypersensitivity, pregnant women, and patients who had received antimicrobials within the previous $72 \mathrm{~h}$, unless those antimicrobials had proved ineffective.

Timentin was administered intravenously. Patients with normal renal function received $3.2 \mathrm{~g}$ ( $3 \mathrm{~g}$ ticarcillin $+0.2 \mathrm{~g}$ clavulanic acid) 4-hourly (7 patients) or 6-hourly

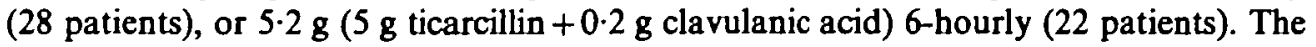
patients with renal failure received $3.2 \mathrm{~g}$ bd, $1.6 \mathrm{~g}(1.5 \mathrm{~g}$ ticarcillin $+0.1 \mathrm{~g}$ clavulanic acid) bd, $5.2 \mathrm{~g}$ bd, or $2.6 \mathrm{~g}(2.5 \mathrm{~g}$ ticarcillin $+0.1 \mathrm{~g}$ clavulanic acid) tds (one patient each dosage). The duration of treatment varied from 2-45 days (mean 12.5 days). Six patients were treated for less than five days either because a side effect (one case) or primary bacterial resistance (five cases) prompted a change of antimicrobial.

Samples of blood and appropriate specimens were collected for culture and susceptibility testing within two days before, and two to five days after commencement of therapy as well as two or three days and one or two weeks after the end of therapy (four weeks for urinary tract infections). Organisms were considered pathogenic if they grew from an appropriate specimen in an appropriate number and if the clinical setting was consistent. Disc diffusion susceptibility testing was performed as proposed by Fuchs et al. (1984).

Blood and urine specimens were drawn for haematological and biochemical investigations before the start of therapy, then at five-day intervals and at the end of therapy. Granulocytopenia was defined as less than 100 neutrophils per $\mu \mathrm{l}$ of blood.

\section{Classification of responses to treatment}

Clinical response. Patients were considered as clinically cured when clinical abnormalities subsided with no evidence of infection when the drug was discontinued or during follow-up; as improved when clinical abnormalities definitely diminished but with incomplete resolution of infection. Clinical failure was defined as no (or only transient) response to therapy. Patients were thought unassessable when they received concurrent appropriate antibiotherapy (with the exception of leukopenic patients receiving Timentin plus amikacin), or when Timentin was replaced at an early stage by other antimicrobials because of either Timentin resistance of the primary pathogen, or because of serious Timentin side effects.

The bacteriological response was classified as follows: eradication when the cultures from the original site of infection became negative; cure when clinical improvement was such that culture material was no longer available; failure when one or more culture sites remained positive for the same organism; relapse when, after becoming initially negative, cultures again grew the same organism; and reinfection when cultures showed secondary growth of another organism.

\section{Results}

Sixty-four episodes were studied in 62 patients. There were 41 males and 21 females, aged from 18 to 85 years (mean 50.5). A large number of associated conditions were present, as shown in Tables II to VIII.

Patient data are detailed in Tables II to VIII and summarized in Table IX. Overall, clinical cure or improvement were achieved in $59 \%$ and $14 \%$ respectively of the 
Table I. Results of susceptibility testing of Timentin and ticarcillin

\begin{tabular}{|c|c|c|c|c|}
\hline \multirow[b]{2}{*}{ Organisms } & \multirow[b]{2}{*}{$\begin{array}{l}\text { No. of } \\
\text { isolates }\end{array}$} & \multicolumn{3}{|c|}{ No. of isolates susceptible to: } \\
\hline & & $\begin{array}{l}\text { Timentin and } \\
\text { ticarcillin }\end{array}$ & $\begin{array}{l}\text { Timentin but } \\
\text { not ticarcillin }\end{array}$ & $\begin{array}{l}\text { Neither Timentin } \\
\text { nor ticarcillin }\end{array}$ \\
\hline E. coli & 13 & 10 & 3 & \\
\hline$P$. aeruginosa & 13 & 10 & 1 & 2 \\
\hline Klebsiella spp. & 5 & & 4 & 1 \\
\hline Proteus spp. & 5 & 5 & & \\
\hline Morganella morganii & 5 & 4 & 1 & \\
\hline Other Gram-negative rods ${ }^{b}$ & 4 & 2 & & 2 \\
\hline S. aureus & 7 & 2 & 5 & \\
\hline Other Gram-positive coccic & 9 & 9 & & \\
\hline Anaerobic bacteria & 9 & 8 & 1 & \\
\hline Totals & 70 & 50 & 15 & 5 \\
\hline
\end{tabular}

Performed by agar diffusion, or broth dilution for anaerobic isolates.

${ }^{b} C$. freundii (1), Ent. cloacae (1), P. cepacia (1), Aeromonas hydrophila (1).

'S. epidermidis (1), Group D, streptococci (5), Str. milleri (2), Group A streptococcus (1).

$\checkmark$ Bacteroides fragills (1), B. ruminicola (1), B. melaninogenicus (2), B. oralis (1), B. thetaiotaomicron (1), Peptococcus species (2), Eubacterium lentum (1).

episodes. Thus, response to treatment occurred in $73 \%$ of the cases. There were 11 failures, while outcome could not be assessed in six cases.

Twenty-one episodes were not bacteriologically proved (of which 13 were fever in leukopenic patients). Among the 43 proved episodes, 25 were thought to be caused by one isolate, nine by two isolates and nine by three isolates. Thus 70 isolates were tested for ticarcillin and Timentin susceptibility (Table I). In five cases infection was caused by a pathogen found to be resistant to Timentin before Timentin administration. In five further cases a Timentin-resistant isolate appeared during treatment. Two patients had a reinfection with Timentin-resistant Escherichia coli and Klebsiella pneumoniae, and this resulted in failure. In three patients Timentin-resistant Citrobacter freundii, Enterobacter cloacae and $P$. aeruginosa respectively appeared after a corresponding Timentin-susceptible strain had been cultivated before treatment. This resulted in failure in two patients, while one patient was cured with concurrent gentamicin therapy to which the organism was susceptible. Of the 26 episodes caused exclusively by isolates susceptible to both Timentin and ticarcillin, $18(69 \%)$ responded, five failed and two were unassessable. In contrast, of the 11 episodes caused by at least one strain susceptible to Timentin but resistant to ticarcillin, five (45\%) responded, four failed and two were unassessable.

\section{Adverse events}

Three patients had side-effects severe enough to stop Timentin therapy. In one patient severe haematuria was accompanied by a prolonged bleeding time and impairment of ADP-induced platelet aggregation. Another patient developed pancreatitis without having any of the risk factors known to be associated with this condition. In both patients the problems resolved after Timentin withdrawal. One cirrhotic patient had a marked weight increase attributed to sodium overload secondary to Timentin administration. Several less serious adverse events were also attributed to Timentin: 


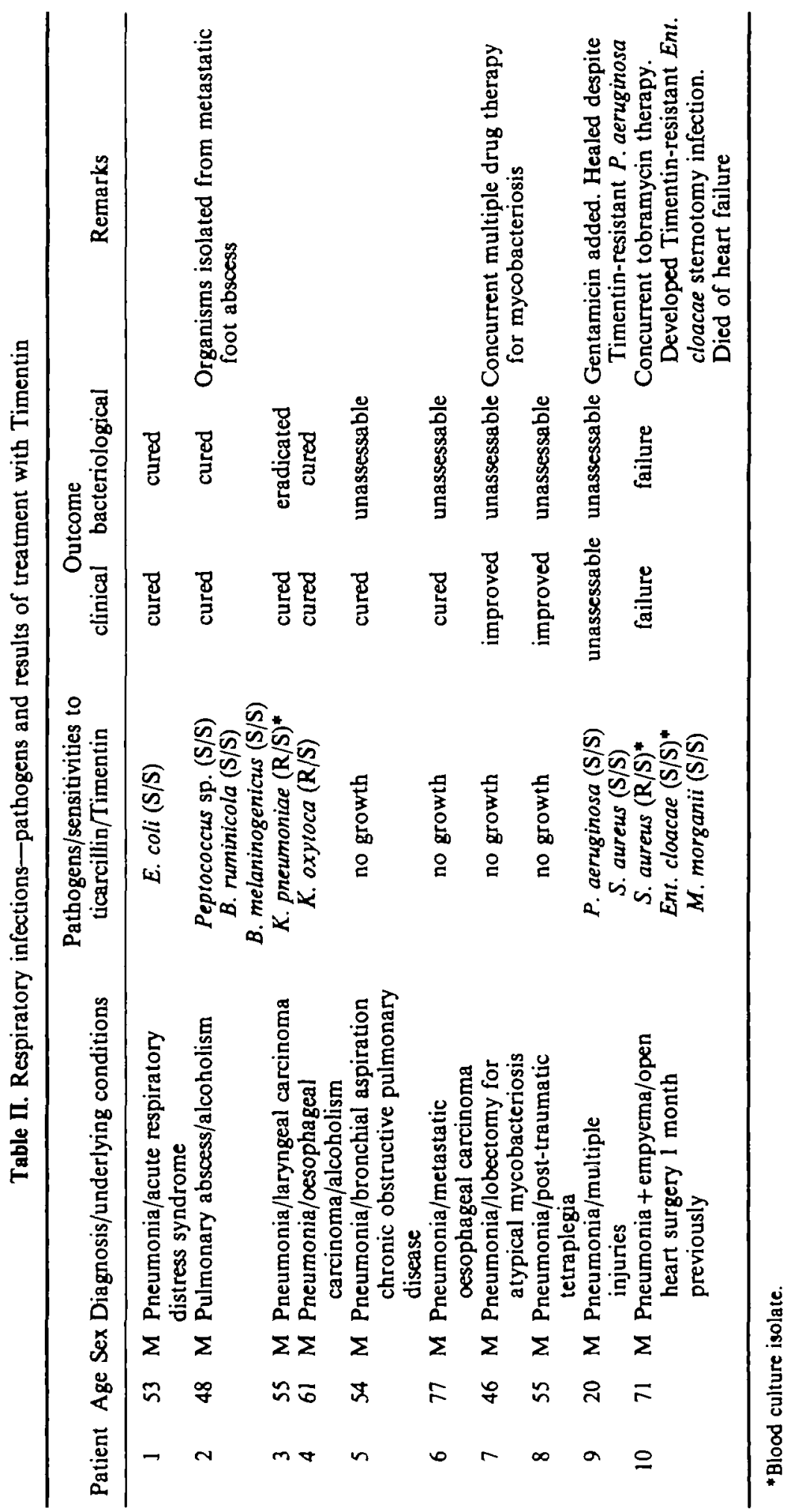




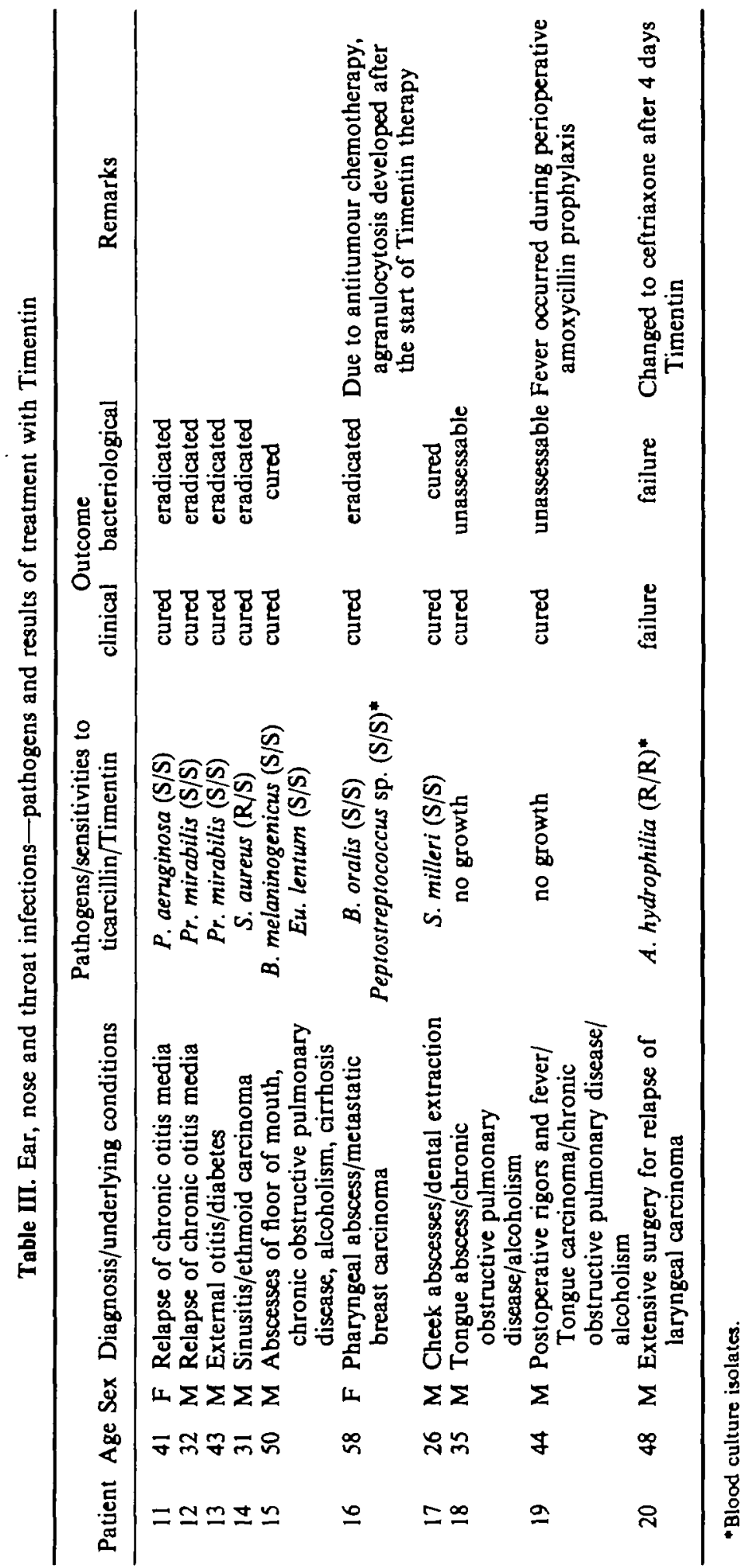




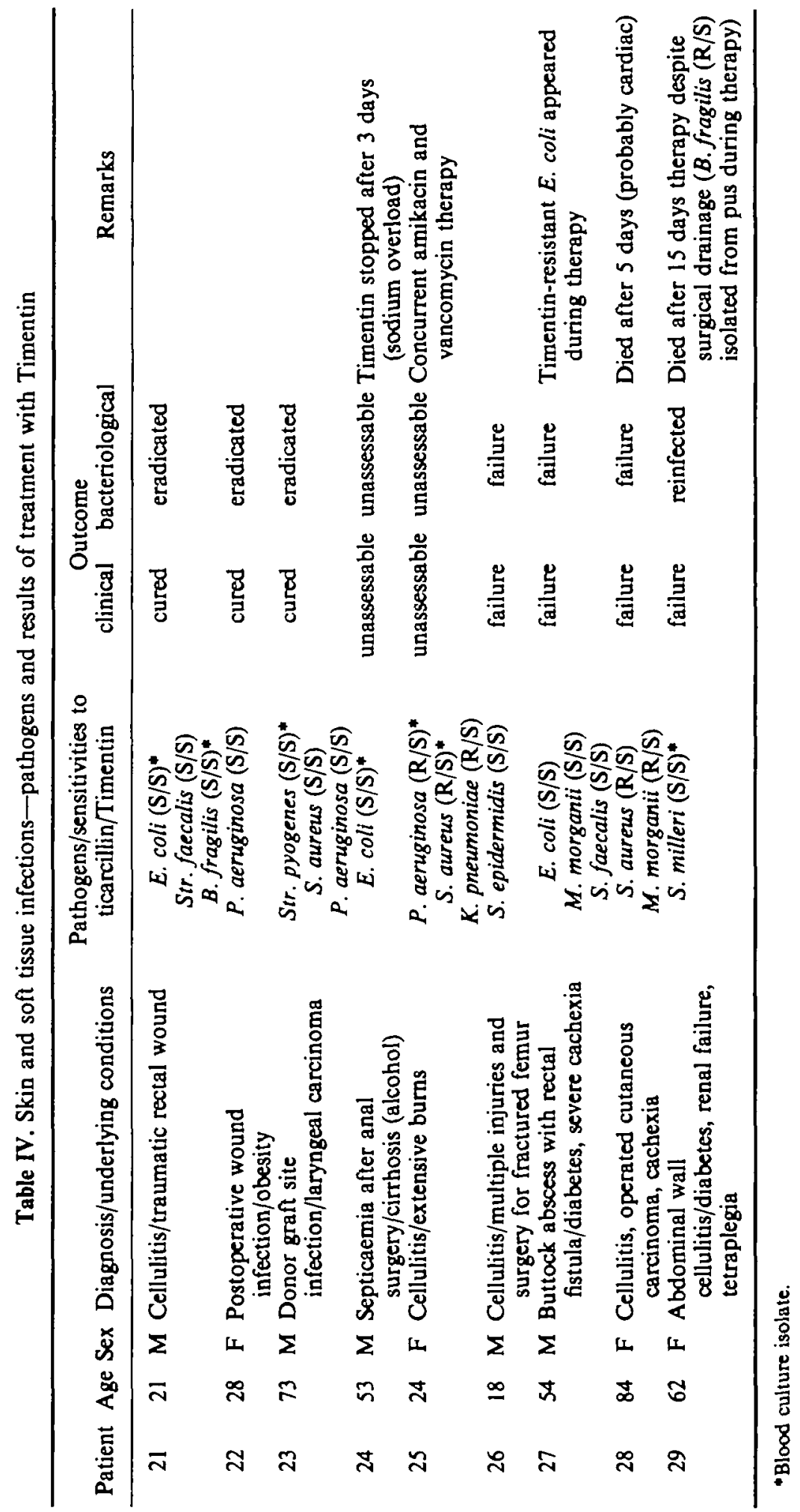


Timentin in hospital infectlons

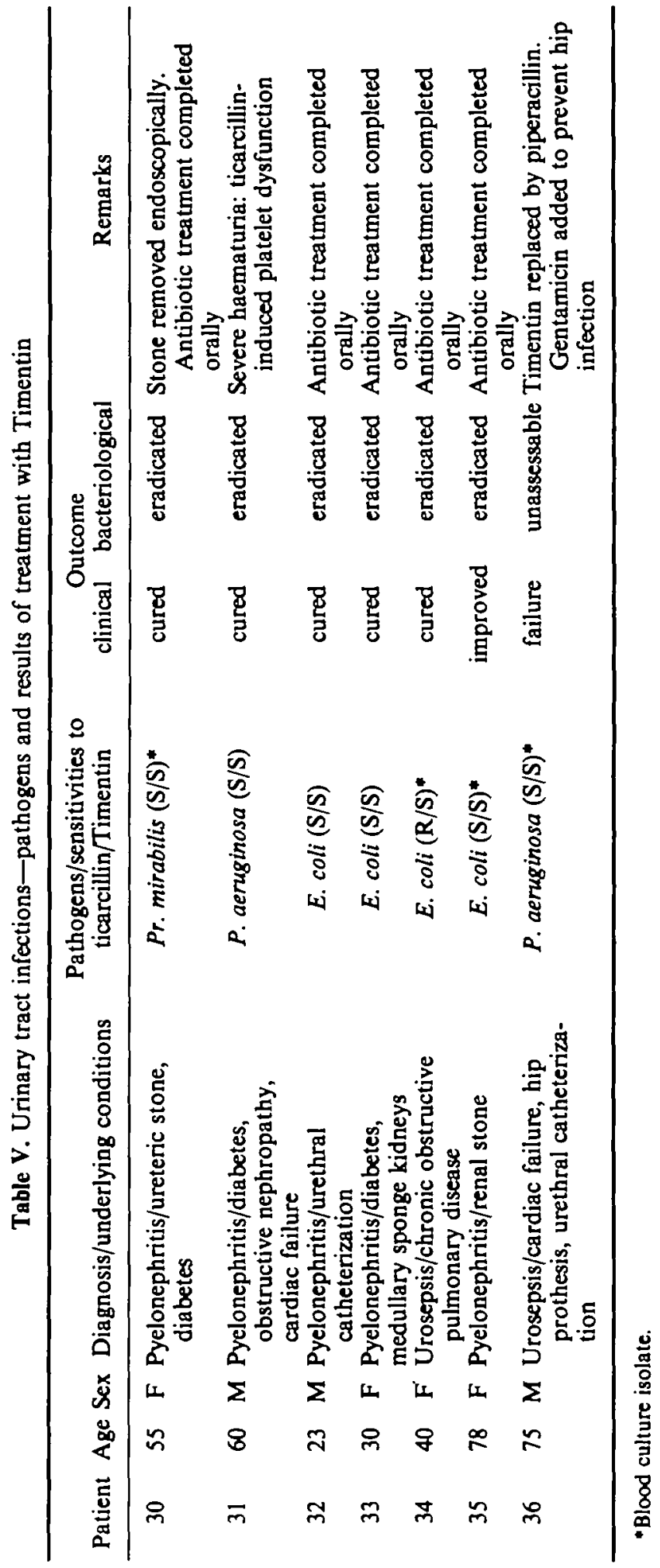




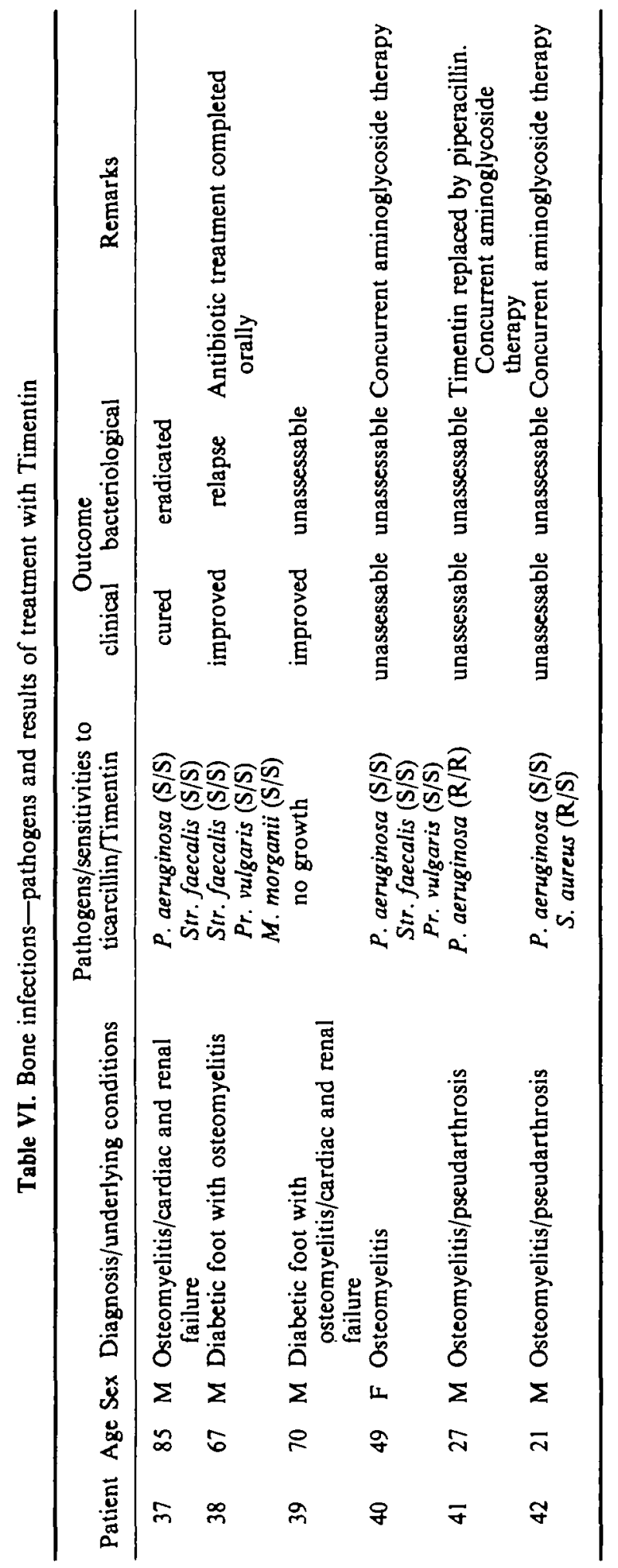


Timentin in hospital infections

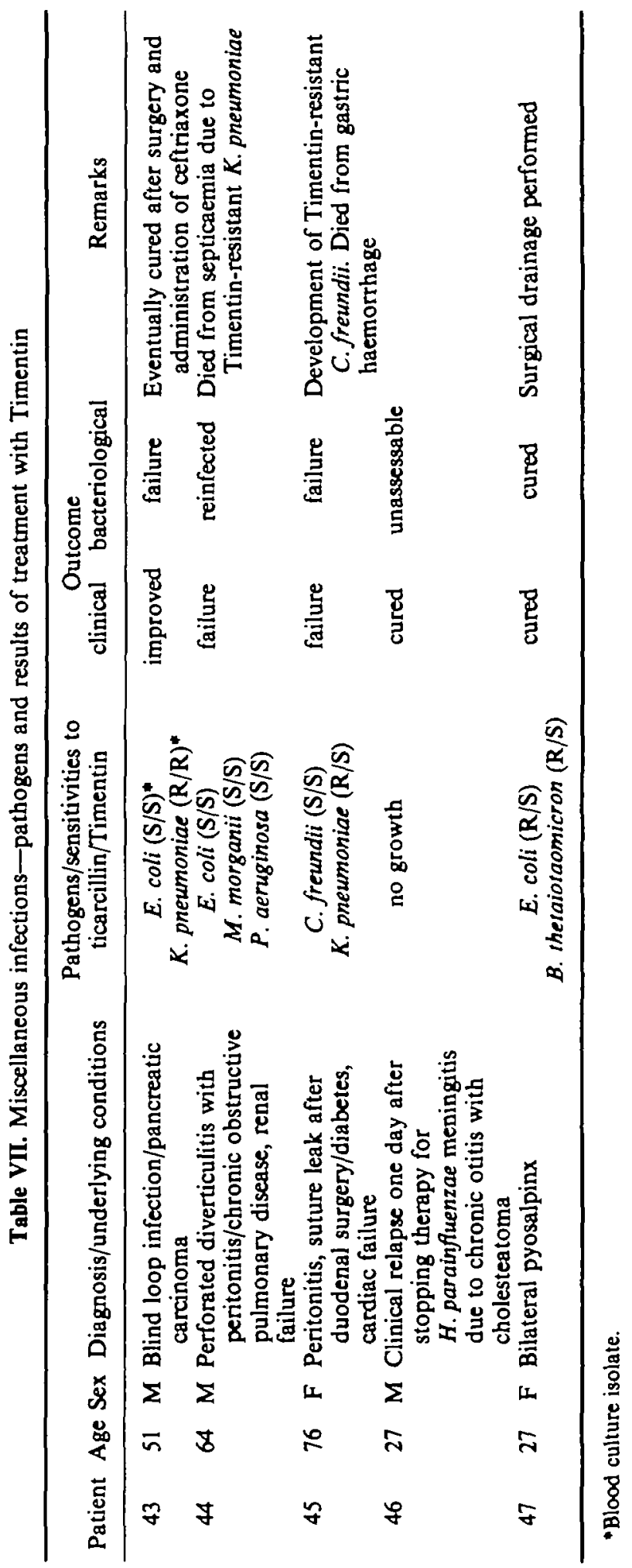




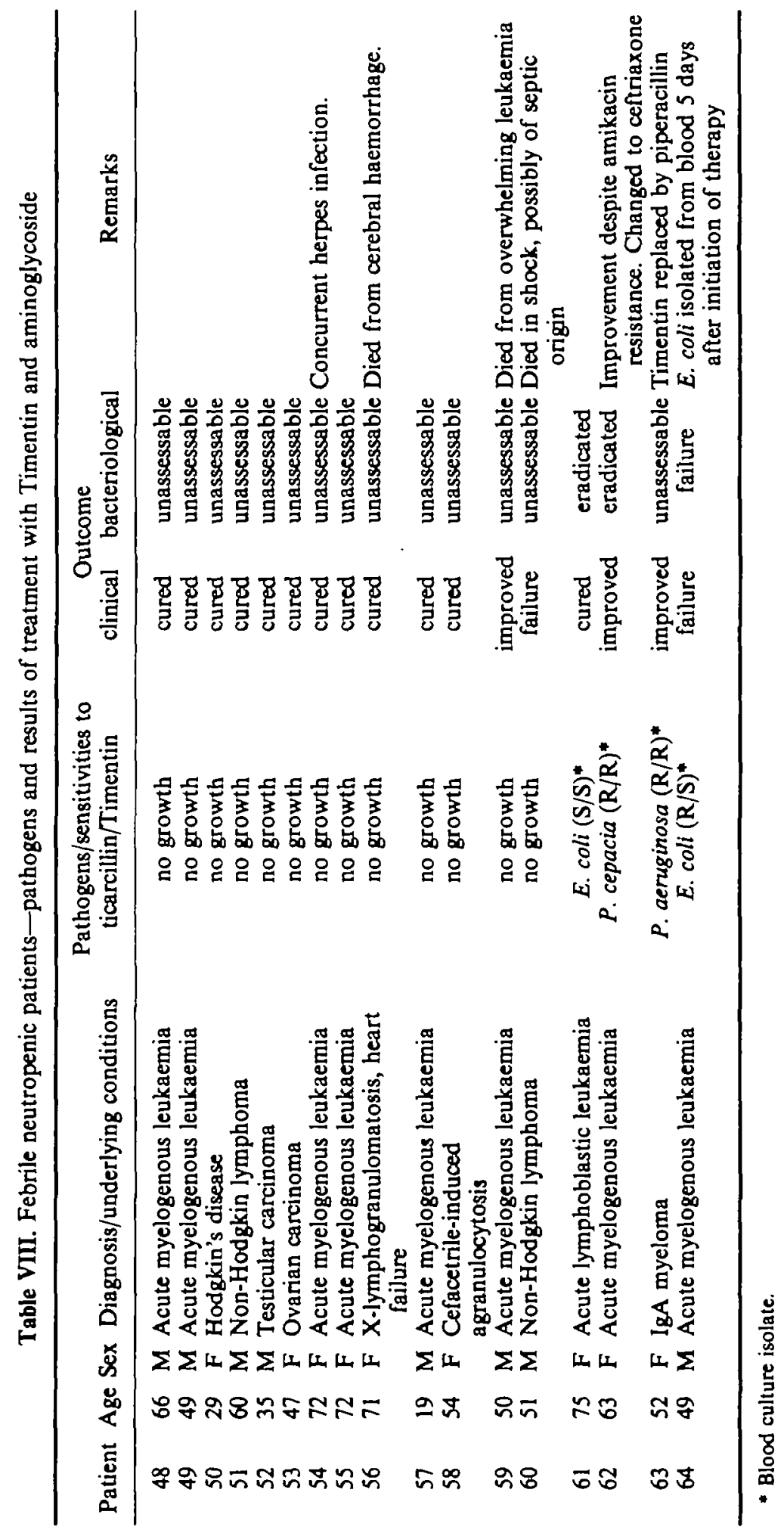




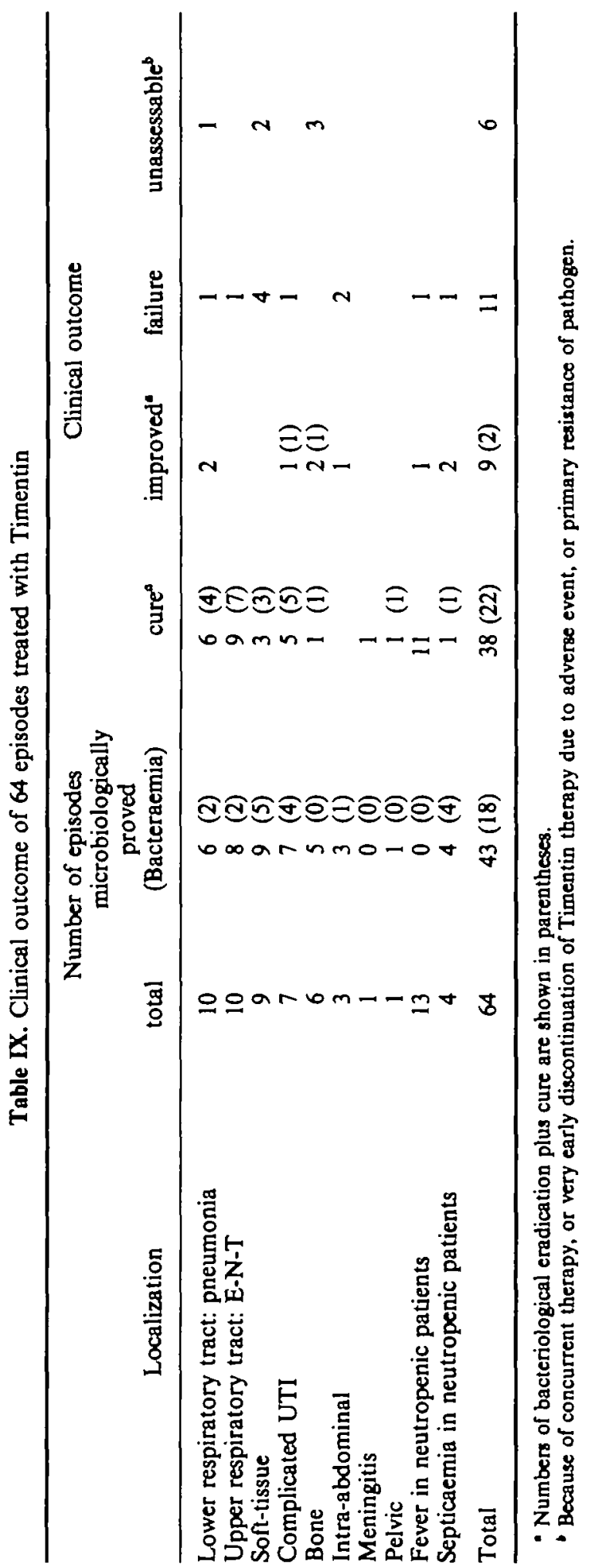


catheter related phlebitis (10), minor changes in liver function tests (4), eosinophilia (2), and thrombocytopenia (1). A positive direct Coombs test developed in seven of 25 patients tested but there was no evidence of haemolysis. Skin rash and diarrhoea were not observed.

\section{Discussion}

This study demonstrates the clinical efficacy of Timentin against severe infections occurring in debilitated patients and due to a wide range of pathogens. However, the response rate $(73 \%)$ is lower than that found in other clinical trials of Timentin (File $e t$ al., 1984; Roselle et al., 1985). In our study, failure mainly occurred in abdominal and soft tissue infections in patients with severe underlying conditions which clearly represented a difficult challenge to antibiotic therapy. Other authors have observed apparently discrepant response rates with other antibiotics such as ceftazidime (Francioli et al., 1983; Hoogkamp-Korstanje, van Erpecum \& van. Kamp, 1985), and ascribed them to differences in the numbers of patients with serious underlying conditions (Hoogkamp-Korstanje et al. 1985).

The appearance of Timentin-resistant isolates may explain some of our treatment failures. In five instances a resistant pathogen appeared during therapy, resulting in four failures; one case was unassessable because of concurrent therapy. In five instances infection was caused by a pathogen found to be resistant to Timentin before Timentin administration. This incidence of Timentin resistance among primary pathogens contrasts with previous findings at our institution. Among 404 blood cultures isolated between 1979 and 1981, only five $P$. aeruginosa were found not to be inhibited by $32 \mathrm{mg} / 1$ ticarcillin in the presence of $5 \mathrm{mg} / 1$ clavulanic acid (Casey \& Glauser, 1983). Although our study population was selected for severe disease caused by multiresistant organisms, these figures may suggest that Timentin resistance is becoming more common in our hospital and it can now be observed in species other than $P$. aeruginosa. The frequent occurrence of mixed infections precluded an analysis of the efficacy of Timentin with respect to the infecting species. However, our data indicate that clavulanic acid did not restore ticarcillin activity against most ticarcillin-resistant $P$. aeruginosa, thus confirming previous reports (Casey \& Glauser, 1983; Fuchs et al., 1984; Barry et al., 1984).

The somewhat lower response rate in patients infected with ticarcillin-resistant but Timentin-susceptible strains, when compared to patients infected by strains susceptible to both antibiotics, is conspicuous but difficult to interpret because the two groups were not comparable, making the significance of the difference questionable.

Timentin was generally well tolerated. Two patients had severe adverse events which could be explained solely on the basis of the known properties of ticarcillin, i.e. a ticarcillin-induced platelet function impairment (Bang \& Kammer, 1983), and a watersodium overload. In one case there was a questionable relationship between Timentin therapy and the development of pancreatitis. In no other instances did an adverse event make discontinuation of Timentin necessary. The high proportion of positive Coombs tests was not unexpected, having been reported by Williams et al. (1985). It is caused by clavulanic acid-mediated non-immune adsorption of plasma proteins on the erythrocyte surface, a phenomenon unassociated with haemolysis.

In summary, Timentin proved to be a safe and effective broad-spectrum agent for the treatment of severe hospital infections. However, development of resistance during 
therapy or reinfection with resistant organisms are a matter of concern, and the need to add an aminoglycoside to Timentin in these settings should be explored.

\section{Acknowledgements}

We thank Beecham AG, Bern, for providing Timentin; Dr P. Francioli, B. Yersin and Dr J. Bille and Dr M. Heitz.

\section{References}

Bang, N. U. \& Kammer, R. B. (1983). Hematologic complications associated with $\beta$-lactam antibiotics. Reviews of Infectious Diseases, Suppl. 2, S380-93.

Barry, A. L., Ayers, L. W., Gavan, T. L., Gerlach, E. H. \& Jones, R. N. (1984). In vitro activity of ticarcillin plus clavulanic acid against bacteria isolated in three centers. European Journal of Clinical Microbiology 3, 203-6.

Casey, P. \& Glauser, M. (1983). Susceptibility of Gram-negative bacteria and Staphylococcus aureus to combinations of ticarcillin and clavulanic acid. European Journal of Clinical Microbiology 2, 541-7.

Clarke, A. M. \& Zemcov, S. J. V. (1984). Clavulanic acid in combination with ticarcillin: an invitro comparison with other $\beta$-lactams. Journal of Antimicrobial Chemotherapy 13, $121-8$.

File, T. M., Tan, J. S., Salstrom, S.-J., Johnson, L. A. \& Douglas, G. F. (1984). Timentin versus piperacillin or moxalactam in the therapy of acute bacterial infections. Antimicrobial Agents and Chemotherapy 26, 310-3.

Francioli, P., Clément, M., Geroulanos, S., von Graevenitz, A., Luthy, R., Regamey, C., Stalder, H., Vogt, M. \& Waldvogel, F. A. (1983). Ceftazidime in severe infections: a Swiss multicentre study. Journal of Antimicrobial Chemotherapy 12, Suppl. A, 139-46.

Fuchs, P. C., Barty, A. L., Thornsberry, C. \& Jones, R. N. (1984). In vitro activity of ticarcillin plus clavulanic acid against 632 clinical isolates. Antimicrobial Agents and Chemotherapy 25, 392-4.

Fuchs, P. C., Jones, R. N., Barry, A. L. \& Thornsberry, C. (1984). Disk diffusion susceptibility testing of ticarcillin plus clavulanic acid. Journal of Clinical Microbiology 19, 555-7.

Hoogkamp-Korstanje, J. A. A., van Erpecum, K. J. \& van Kamp, H. (1985). Ceftazidime in serious hospital-acquired infections. Journal of Antimicrobial Chemotherapy 15, 743-9.

Hunter, P. A., Coleman, K., Fisher, J. \& Taylor, D. (1980). In vitro synergistic properties of clavulanic acid, with ampicillin, amoxycillin and ticarcillin. Journal of Antimicrobial Chemotherapy 6, 455-70.

Lamothe, F., Auger, F. \& Lacroix, J.-M. (1984). Effect of clavulanic acid on the activities of ten $\beta$-lactam agents against members of the Bacteroides fragilis group. Antimicrobial Agents and Chemotherapy 25, 662-5.

Neu, H. C. \& Fu, K. P. (1978). Clavulanic acid, a novel inhibitor of $\beta$-lactamases. Antimicrobial Agents and Chemotherapy 14, 650-5.

Roselle, G. A., Bode, R., Hamilton, B., Bibler, M., Sullivan, R., Douce, R., Staneck, J. L. \& Bullock, W. E. (1985). Clinical trial of the efficacy and safety of ticarcillin and clavulanic acid. Antimicrobial Agents and Chemotherapy 27, 291-6.

Williams, M. E., Thomas, D., Harman, C. P., Mintz, P. D. \& Donowith, G. R. (1985). Positive direct antiglobulin tests due to clavulanic acid. Antimicrobial Agents and Chemotherapy 27, 125-7. 